\title{
Global Stable Disease in Skin
}

National Cancer Institute

\section{Source}

National Cancer Institute. Global Stable Disease in Skin. NCl Thesaurus. Code C159954.

Less than 25 percent increase to less than 50 percent clearance in skin disease from baseline without new tumors (T3) in patients with T1, T2, or T4, only skin disease. 